\title{
Application of HEC-HMS Model to Estimate Daily Streamflow in Badddegama Watershed of Gin Ganga Basin Sri Lanka
}

\author{
J.M.L. Madhushankha and N.T.S. Wijesekera
}

\begin{abstract}
Rapid urbanization causes stress in limited water resources. Water managers need quantified streamflow as high, medium and low flow regions to assess and manage water resources. This requires calibrated and validated models together with a rationalized method for the selection of a proper model, components, data, temporal resolution, objective function, and performance criteria. The current preference is to use process-based models for streamflow modelling. The widely used process-based HEC-HMS 4.2.1 version model was chosen to simulate daily streamflow at Baddegama watershed $\left(749 \mathrm{~km}^{2}\right)$ while using 2007 to 2012 period for calibration, and 2013 to 2017 for verification. Simple canopy, initial deficit and constant loss, SCS direct runoff, and recession baseflow were selected as model components. Semi-automatic optimization was done with RMSE objective function. Model was calibrated and validated with RMSE of $3.0 \mathrm{~mm} /$ day and $3.5 \mathrm{~mm} /$ day. Model with RMSE value of $6.2 \mathrm{~mm} /$ day for high flows and $2.3 \mathrm{~mm} /$ day for medium flows indicate better capability of model on flooding management and water resource. The HEC model showed very good matching of daily flows in the high and intermediate regions but reflected a poor matching in the low flow region. Hence the use of HEC-HMS model for the considered regions can be recommended for flood and water resources management. The use of HECHMS for low flow management must be with caution.
\end{abstract}

Keywords: $\quad$ Process-based Model, HEC-HMS, RMSE, Calibration \& Verification

\section{Introduction.}

Existing water resources and future water demands should be assessed in order to evaluate the impacts on society and the environment because of any planned water infrastructure development [1]. Hence, such assessments performed in a reliable manner are vital for sustainable water resources management.

Hydrological processes in a watershed are complex. Representation of processes in a watershed using scientific methods is needed to simulate these hydrological processes accurately. A sufficient collection of a continuous series of streamflow (SF) data is necessary to perform sustainable water resource management using scientific watershed models [2]. However, lack of past observations and advances in technology have caused problems when using hydrological models to quantify streamflow [3]. Loucks [4] had mentioned that hydrological models are versatile tools to manage watersheds by evaluating the upcoming effects of proposed water management plans. Along with the advantage of scientific representation, a process-based model enable the incorporation of hydrological processes with space-time variability [5].

Comprehensive physically-based distributed models require information such as land use, meteorological data and properties of the watershed for their parameterization and adjustment [6]. Though there is a preference to use elaborate models, the data constraints must be carefully considered when an appropriate model is selected for a particular catchment to ensure optimum watershed management [7], [8]. However, main problem is the lack of guidance to select a suitable rainfall-runoff model. A suitable hydrologic model can be selected by using several selection criteria.

\footnotetext{
Eng. J.M.L. Madhushankha, AMIE(SL), M.Sc, B.Sc. Eng.

(Hons) (Moratuwa), Lecturer, Department of Limnology and Water Technology (FMST), University of Ruhuna,

Sri Lanka.

Email:lalanimadhusankha@gmail.com

ORCID ID: https://orcid.org/0000-0001-9325-9756

Eng. (Snr. Prof.) N.T.S. Wijesekera, C.Eng., FIE(SL),

MIECE (UK), B.Sc. Eng.Hons (Peradeniya), PG

Dip(Moratuwa), M.Eng. (Tokyo), Ph.D(Tokyo), Chairman,

Construction Industry Development Authority (CIDA),

Senior Professor, Department of Civil Engineering,

University of Moratuwa, Sri Lanka.

Email:sohanw2@gmail.com

ORCID ID: https://orcid.org/0000-0003-0964-4331
} 
Criteria of selection mainly depend on the specification of a particular project [9].

Mimicking the physical processes in a watershed by using a process-based model requires the inclusion of fundamental governing equations to represent each representative process of the hydrologic system [6]. The most widely accepted physically-based models which are lately developed or regularly updated can be named as GSSHA, HSPF, KINEROS2, HEC HMS, AnnAGNPS, SWAT, GSSHA, WinSRM, PRMS, HYPE, WetSpa, and MIKE-SHE [10], [11]. With compared to recently developed and updated models, HECHMS is providing more options to simulate [11].

HEC HMS is a free watershed model widely applied in the world and to a certain extent in Sri Lanka [12]-[15]. HEC HMS model is relevant to different kinds of geographic areas for solving watershed issues [16]. In case of Sri Lanka, Siriwardana \& Wijesekera indicated that HEC HMS model would be a better option for planning irrigation reservoirs in ungauged watersheds [14], Jayadeera \& Wijesekera concluded that capability of model on flood and water resource management at Kalu Ganga basin by evaluation of potential water management [13]. Present work is carried out to estimate and assess daily streamflow at Baddegama watershed by application of HECHMS 4.2.1 version model for sustainable water resource management.

\section{Study Area}

Gin ganga, the fifth largest river in Sri Lanka, is located approximately between longitudes $80^{\circ} 08^{\prime \prime} \mathrm{E}$ and $80^{\circ} 40^{\prime \prime} \mathrm{E}$, and latitudes $6^{\circ} 04^{\prime \prime} \mathrm{N}$ and $6^{\circ} 30^{\prime \prime}$ N. Gin Ganga basin is entirely located in the wet zone and faces frequent flooding. Sandy clay loam is the main soil type in the watershed and temperature varies from $24^{\circ} \mathrm{C}$ to $32^{\circ} \mathrm{C}$. The watershed has a considerable rainforest cover in its upper watershed [17]. The river gauging stations and rainfall stations with monthly variation of rainfall are shown in Figure 1. The studied watershed area covers approximately $749 \mathrm{~km}^{2}$.

\section{Methodology}

\subsection{Data and Data Checking}

Daily rainfall (RF) data of six rainfall stations at Thawalama, Anningkanda, Deniyaya, Neluwa,
Hiniduma, Baddegama, monthly evaporation data at Kottawa (nearly $18 \mathrm{~km}$ away from Baddegama river station) and daily streamflow at Baddegama were collected for the period from 2007 to 2017. Kottawa is the only nearest evaporation station which is having high percentage of available data for the selected period. The latest data period from 2007 to 2017 has been selected because higher percentage of availability of data and lesser percentage of data missing.

Land use, topographic and contour data in 1:50000 scale were collected from the Department of Survey. Annual water balance (AWB) was performed to check the water budget at each water year. Visual data checks were done to identify anomalies of the pattern. Daily rainfall vs streamflow variations at each station were plotted and compared. Double mass curves were plotted for all the stations to check consistency of data and no data inconsistency could be observed. Thiessen average rainfall vs streamflow graphs indicated that use of $2007 / 08$ and $2008 / 09$ water years data needs caution. 2007/08 and 2014/15 are the highest rainfall water years. 2011/12 and 2013/14 years indicated the driest years.

\subsection{Model Development}

\subsubsection{Meteorology Model}

Thiessen polygon mean areal precipitation computing method is most widely used for continuous HEC-HMS modelling. Thiessen method computes station weights by considering that the locations of stations are fixed [18], [19]. Theisen weights for RF stations at Hiniduma, Deniyaya, Anningkanda, Baddegama, Neluwa and Thawalama are, 0.27, $0.18,0.06,0.23,0.18,0.08$, respectively.

\subsubsection{Basin Model}

A lumped model was developed for Baddegama watershed because lumped modelling approach is a good alternative to the complex physically-based models when the main focus is only streamflow prediction [20]. The model components, objective function, flow thresholds for evaluation, model evaluation criteria, calibration and verification requirements were selected for this task by comparing other options with its relevance to the purpose of the current study. As a model structure, only one sub basin was selected from the basin model to represent a lumped model. There was no reach and junction components since river routing was not considered for lumped model. 


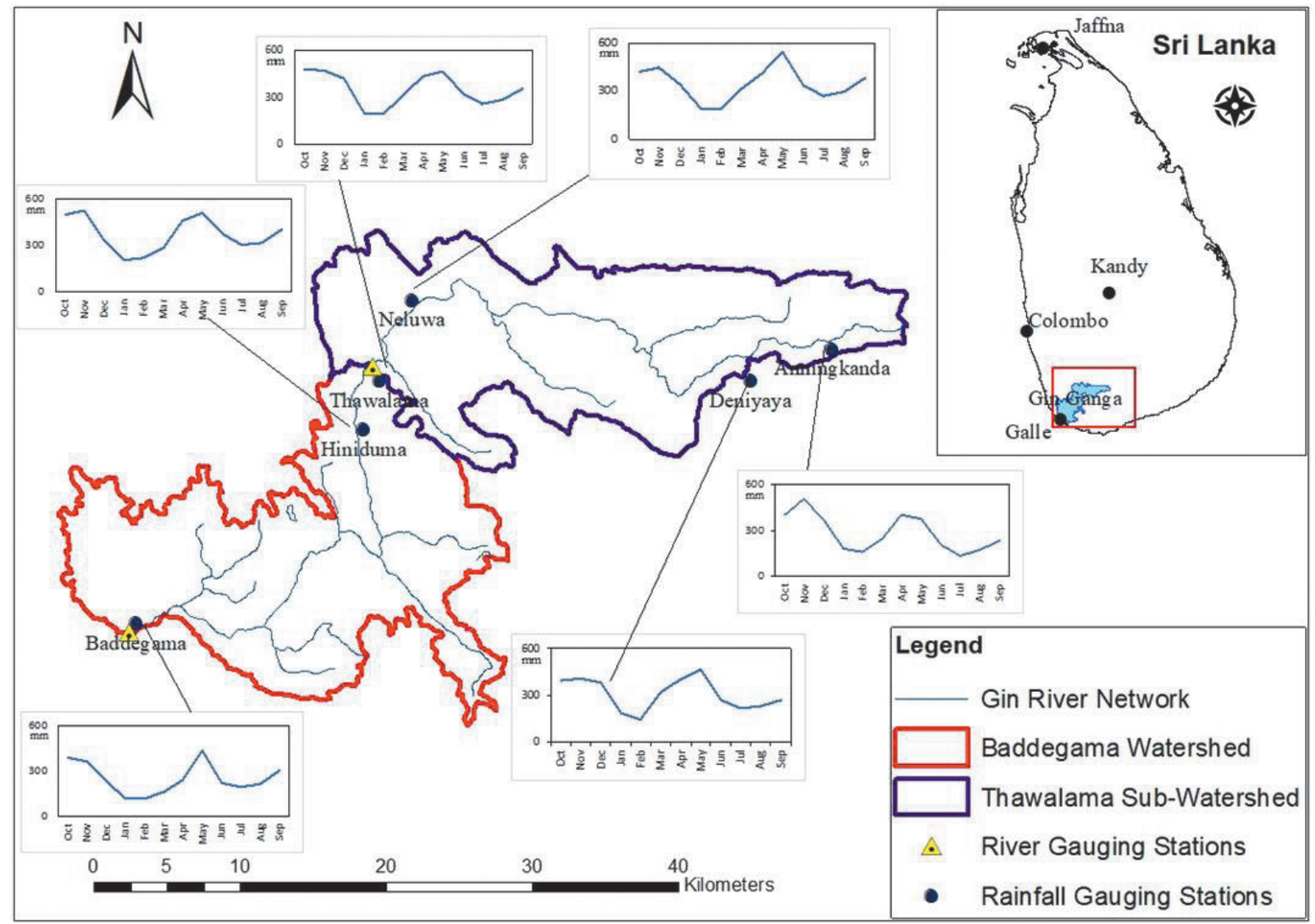

Figure 1 - Study Area at Baddegama with Monthly Variation of Rainfall at Each Station

\subsubsection{Canopy Model}

Model's user manual clearly states that canopy interception should be incorporated with an initial deficit and constant method in continuous modelling [21], [16]. In order to represent interception and evapotranspiration, user can select the canopy component from the three methods that are available, as dynamic, simple and gridded simple canopy [16]. Simple canopy is preferable for this study because of the compatibility with the loss method and applicability in continuous process [22]. This value may be very small because of the high impervious percentage of $40 \%$ at Baddegama. Impervious percentage was determined by the percentage of homestead and rock land use percentage from land use distribution at Baddegama. Initial canopy storage was estimated by optimization while considering both dry and wet seasons to determine evapotranspiration.

\subsubsection{Precipitation Loss Model}

Various methods are available to simulate losses. Event modelling consists of several options as initial constant, SCS CN (Soil Conservation Service Curve Number), Exponential, Green Ampt, and Smith Parlange. For primary continuous modeling, usually Deficit and constant loss method was used. This study also used Deficit and constant loss method because it considers the regain of initial loss after a protracted duration of no rainfall. Also it is most suitable for continuous simulation and having a smaller number of parameters [23].

Initial deficit, maximum deficit and constant loss rate are the parameters of selected loss method and those were estimated by optimization. Initial values for the parameters were estimated as follows.

Initial value of constant loss rate was taken as $1.27 \mathrm{~mm} / \mathrm{hr}$ which is the minimum loss rate given for hydrological soil type $C$ [21]. The weighted $\mathrm{CN}$ value of 79.9 was computed by averaging $\mathrm{CN}$ values for each land use type which is from the standard tables for AMC (antecedent moisture condition) II and type C hydrological soil group [24]. SCS abstraction method formula was used to determine maximum potential retention which was taken as the maximum deficit. The initial deficit parameter was computed by the formula which provided initial abstraction as equal to maximum retention times 0.2 [24]. Table 3 shows this initial parameter values of the Baddegama watershed. 


\subsubsection{Transform Model}

HEC HMS provides seven options to convert excess rainfall into direct runoff [16]. SCS method was used because i) SCS method adaptation in various environments and generate better results; ii) only two types of parameters make easy calculation; and iii) reliable and excellent results can be obtained as same as complex models [25]. Lag Time is the only parameter in SCS UH method and it was calculated by considering the relationship of lag time with time of concentration (TC). TC was calculated using the Kirpich formula. Lag time for watershed was calculated as $3220 \mathrm{~min}$.

\subsubsection{Baseflow Model}

To represent baseflow, five methods are available in model [16]. Baseflow was calculated by the exponential recession method because its applicability in continuous process [26], lesser number of parameters and the compatibility with loss model. Sri Lankan studies used baseflow recession because its ability to automatically reset after each storm event [13]-[15]. Recession baseflow model consists of three parameters such as initial discharge, recession constant and ratio to peak. In this, ratio to peak was taken as 0.2 and it was justified by comparing the behaviour with the observed hydrographs. Groundwater flow recession constant was taken as 0.95 by selecting from typical values proposed for watershed area range $300 \mathrm{~km}^{2}-1600 \mathrm{~km}^{2}$ [21]. Initial discharge at the beginning was taken as the initial baseflow value [22].

\subsection{Model Evaluation}

Model evaluation was carried out using six criteria. They are 1) annual water balance; 2) hydrograph matching; 3) flow duration curve (FDC) matching; 4) FDC matching for high flows; 5) FDC matching for medium flows; and 6) FDC for low flow matching.

\subsubsection{Flow Threshold Separation}

According to the order of magnitude of probability of exceedance and variation of corresponding FDC gradient, $15 \%$ and $70 \%$ probability of exceedance, were selected as high and low flow thresholds (Figure 2) for Baddegama watershed [27].

\subsubsection{Objective Function}

In this study, RMSE was selected as the objective function because it is most widely used to compare observed and estimated streamflow in HEC HMS [28]. HEC HMS model has two automatic optimization search algorithms, namely Univariate Gradient (UG), and Nelder and Mead (NM) methods [29]. The NM search algorithm is used to improve search direction [30]. The NM method is used more frequently than the UG method. This is mainly because the NM method uses a downhill simplex to assess all parameters simultaneously [20]. Considering these reasons, NM was used for this study. Fully automatic calibration results were not good and a semi-automatic calibration approach was used to optimize the parameters.

\subsubsection{Simulation Controls}

HEC HMS guide recommends that simulation time interval should not exceed 0.29 times lag time for a sub basin [21]. Accordingly, 6 hours simulation time interval was selected. Beginning and end of the date from 2007 to 2012 period was taken as calibration period. A five time repetition of calibration data set was used to warmup the model to reduce the effect of initial conditions [31]. Warmup period was adequate to stabilize the initial conditions for water year. Data from 2013 to 2017 was used for model verification.

\section{Results}

\subsection{Watershed Status}

Average annual rainfall, streamflow and evaporation over the study period are 3857 $\mathrm{mm}, 2802 \mathrm{~mm}$ and $913 \mathrm{~mm}$, respectively. Runoff coefficient during the period 2007 to 2017 varied between 0.7 and 0.8 . The highest runoff coefficient value was indicated in the 2015/16 water year while the 2013/14 water year indicating the lowest value for the runoff coefficient. The lowest and highest evaporation values can be seen in 2014/15 and 2008/09 water years, respectively. Baddegama daily streamflow indicates high low flows during less rainfall period throughout the calibration and verification period. This may be due to the closeness of river gauge to the sea and flat terrain. However, data collection station's authorities confirmed that there is no backwater effects at the Baddegama gauge even though there is a saltwater barrier. These were the observations about the streamflow at Baddegama.

\subsection{Calibration and Verification}

The model performance evaluation results for the entire period, high, medium and low flow periods, during both calibration and verification are shown in Figures 3 to 6 . Calibration and verification results show good 
overall matching in hydrograph (Table 1). In Figures 3 and 5, most of the high peaks were captured by the model but there were shifts in the magnitude of peak flow occurrence in small peaks.

Table 1 - Performance Evaluation of the Continuous HEC- HMS Model

\begin{tabular}{|c|c|c|}
\hline Criteria No & Calibration & Verification \\
\hline 1 & $-0.30 \%$ & $-16.69 \%$ \\
\hline \multicolumn{2}{|l|}{ RMSE (mm/day) } \\
\hline 2 & 3.08 & 3.55 \\
\hline 3 & 3.08 & 3.55 \\
\hline 4 & 6.28 & 7.45 \\
\hline 5 & 2.32 & 2.58 \\
\hline 6 & 1.21 & 1.21 \\
\hline
\end{tabular}

Table 2 - Annual Water Balance Comparison

\begin{tabular}{|c|c|c|c|c|}
\hline $\begin{array}{c}\text { Water } \\
\text { year }\end{array}$ & RF & Obs SF & Sim SF & $\begin{array}{c}\text { AWB } \\
\text { Error }\end{array}$ \\
\hline \multicolumn{5}{|c|}{ Calibration (mm/year) } \\
\hline $2007 / 08$ & 4245 & 3311 & 3379 & 67 \\
\hline $2008 / 09$ & 3754 & 2681 & 2646 & -35 \\
\hline $2009 / 10$ & 3795 & 2741 & 2740 & -2 \\
\hline $2010 / 11$ & 4004 & 2992 & 3011 & 19 \\
\hline $2011 / 12$ & 3313 & 2430 & 2365 & -65 \\
\hline \multicolumn{5}{|c|}{ Verification (mm/year) } \\
\hline $2012 / 13$ & 4098 & 3080 & 3318 & 237 \\
\hline $2013 / 14$ & 3527 & 2371 & 2298 & -73 \\
\hline $2014 / 15$ & 4461 & 2995 & 2437 & -558 \\
\hline $2015 / 16$ & 3517 & 2851 & 2089 & -762 \\
\hline $2016 / 17$ & 3853 & 2571 & 2795 & 223 \\
\hline
\end{tabular}

It may be due to spatial variation of rainfall. Model showed a poor matching of streamflow during dry period. Hence water management during dry periods by using this model should be carried out with caution. During the wet season, model showed a good matching for all flow components. FDC during calibration (Figure 4) also showed that the model does respond well during low flow periods but verification (Figure 6) period indicates poor matching. In both calibration and verification periods, model does not reach the best fitted of highest flow values. The annual water balance in calibration and verification periods were 3 $\mathrm{mm}$ and $187 \mathrm{~mm} /$ year (Table 2), respectively. The optimised parameters are in Table 3.

Table 3 - Optimized Model Parameter

\begin{tabular}{|l|c|c|c|}
\hline Parameters & Units & Initial & Optimized \\
\hline Constant Rate & $\mathrm{mm} / \mathrm{hr}$ & 1.27 & 1.00 \\
\hline Initial Deficit & $\mathrm{mm}$ & 12.74 & 12.998 \\
\hline $\begin{array}{l}\text { Maximum } \\
\text { Deficit }\end{array}$ & $\mathrm{mm}$ & 63.7 & 50.483 \\
\hline $\begin{array}{l}\text { Initial } \\
\text { Discharge }\end{array}$ & $\mathrm{m}^{3} / \mathrm{s}$ & 42 & 42.6 \\
\hline Ratio to Peak & $\mathrm{min}$ & 3220 & 3268 \\
\hline $\begin{array}{l}\text { Recession } \\
\text { Constant }\end{array}$ & $\%$ & 0.001 & 0.0022648 \\
\hline Lag Time & $\mathrm{mm}$ & 0.456 & 0.42571 \\
\hline $\begin{array}{l}\text { Initial Canopy } \\
\text { Storage }\end{array}$ & & & 0.9985 \\
\hline $\begin{array}{l}\text { Maximum } \\
\text { canopy storage }\end{array}$ & \multicolumn{2}{|l}{} \\
\hline
\end{tabular}

Figure 2 - Flow Threshold Separation by Daily FDC and FDC Gradient at Baddegama (10 - Water Year Data) 


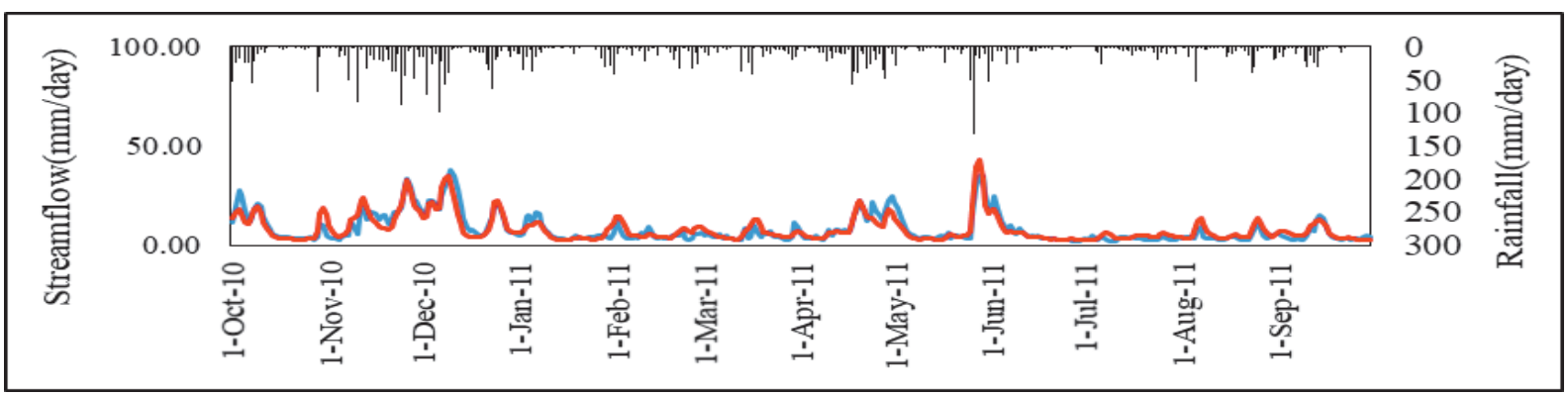

Figure 3 - Streamflow Comparison (Calibration)

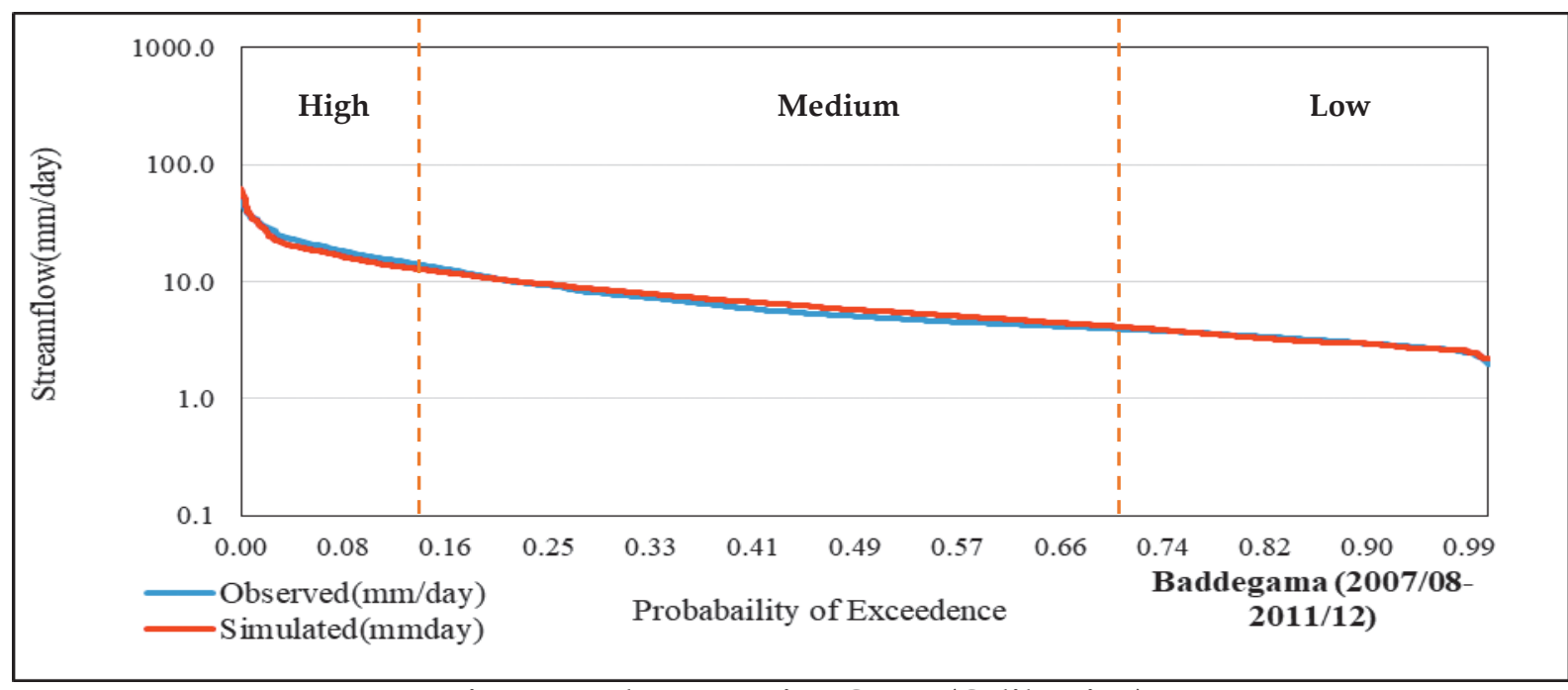

Figure 4 - Flow Duration Curve (Calibration)

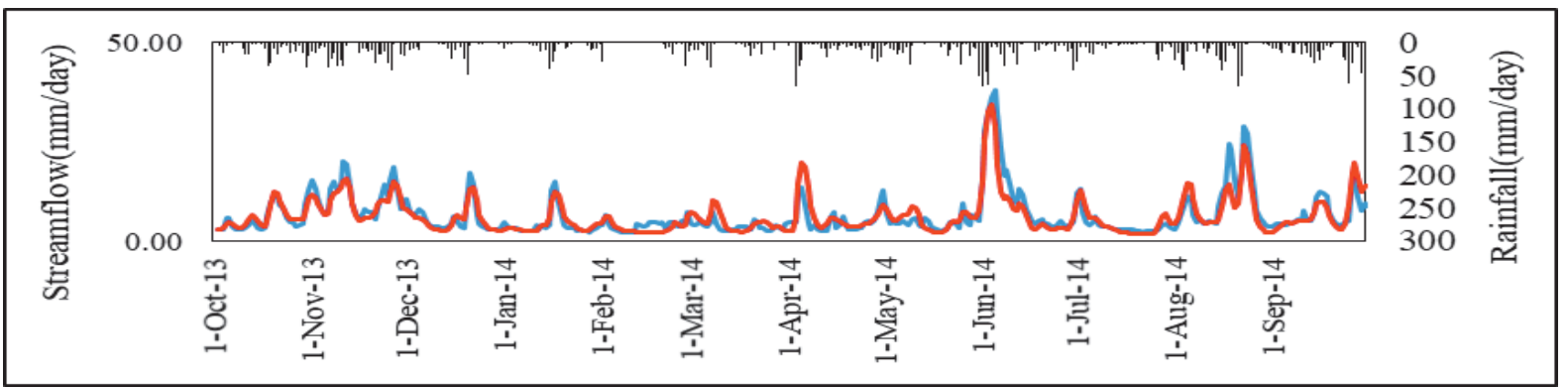

Figure 5 - Streamflow Comparison (Verification)

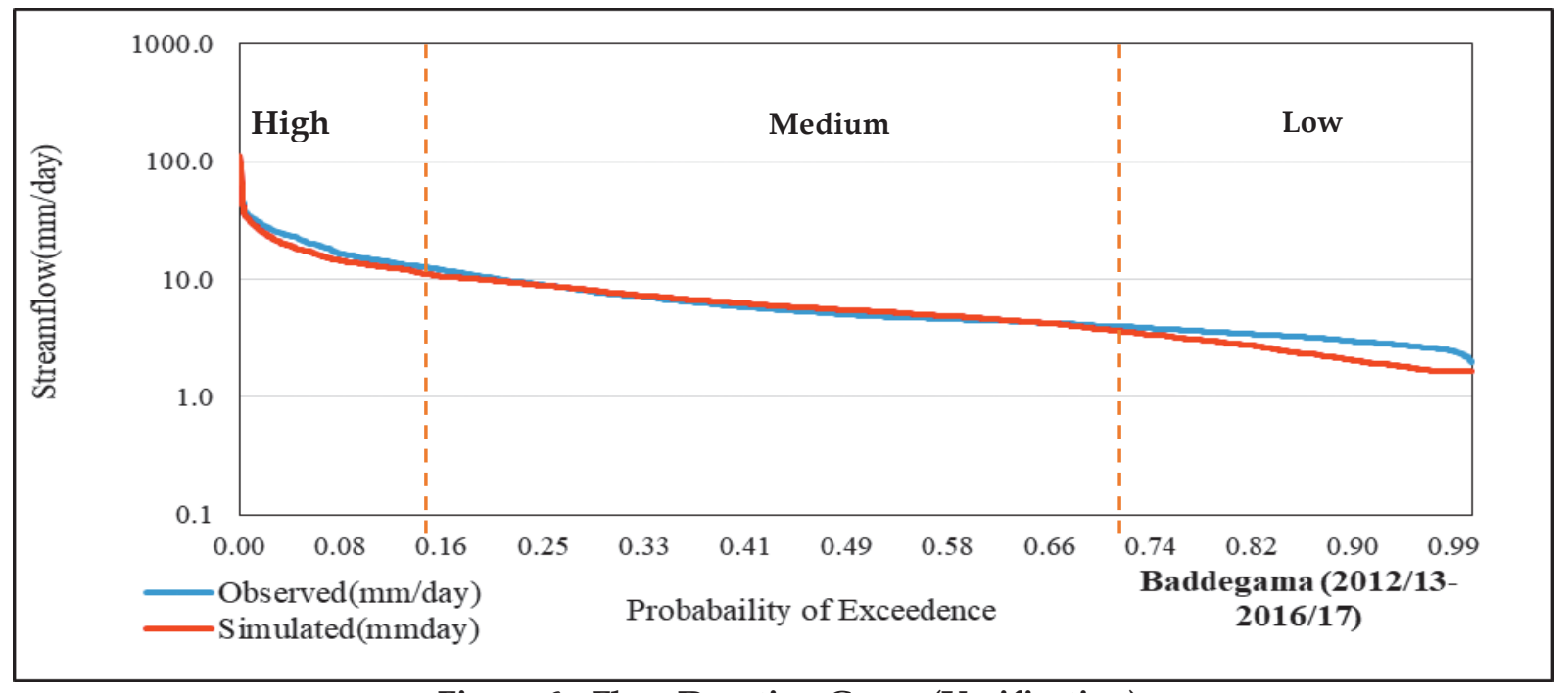

Figure 6 - Flow Duration Curve (Verification) 


\section{Discussion}

\subsection{Model Component Selection}

The crucial decision of this study was the selection of appropriate model components according to the study objective. Canopy, precipitation loss, transform and baseflow components need most relevant method to calculate streamflow accurately. According to several criteria and justification by literature, sub models were selected as simple canopy, initial deficit and constant, SCS UH for transform, and exponential recession base flow. Hydrograph (Figure 3 and Figure 5) for the entire period showed that similar pattern and magnitude of simulated streamflow with compared to observed. Therefore, selected components are capable to simulate most accurate streamflow at Baddegama.

\subsection{Model Performance}

Evaluation criteria and objective function are key factors to assess the model. In this study, a total six number of criteria were considered to evaluate the model. Table 2 indicates that lesser annual water balance percentage error for calibration with compared to verification. However, hydrograph error matching is not showing that much error difference between calibration and verification. FDC for high flow error shows that higher deference of error between calibration and verification periods. Hence, one evaluation criteria is not sufficient to justify the model performance. Therefore, evaluation of all these six categories together causes to indicate a better picture of developed model performance.

RMSE objective function was taken to optimized Baddegama model. In this study $\mathrm{mm}$ /day is the unit for RMSE. RMSE statistic considers an average of deference between observed and simulated. Therefore, when optimization running, it is more favourable to high flows. However, just focusing only on low flow region affects the matching of medium and high flow regions during optimisation. In optimisation, RMSE objective function was able to give best fit to high and moderate flows with more considerable matching to low flow regions. Hence, objective function is key factor to develop a reliable model.

\subsection{Model Calibration}

Satisfactory RMSE value of 3.08 and 3.55 $\mathrm{mm}$ /day indicated in hydrograph matching in calibration and verification, respectively.
According to model evaluation guideline, ratio of RMSE to the standard deviation of measured data is considered to evaluate model performance. The ratios are 0.46 and 0.53 for calibration and validation, respectively. It indicates very good model performance rating for calibration, and good performance rating for verification ([32], [33]). Hydrographs in both periods reveal that matching of flow pattern is not satisfactory, especially in low flows, while RMSE reflects acceptable less error values. Hence, hydrograph matching in low flows needs more improvement. However, similar pattern fittings of peaks in hydrographs reveal Baddegama model's capability to use in flood management.

During the wet season all regions of flow show a considerable level of matching at both periods. However, during dry season, models were not capable to respond to lesser rainfall and high rainfall after dry or no rainfall period. This may be due to spatial variabilities of rainfall over the watersheds and may be some observe data errors in some years. These reasons may lead to a high objective function value during calibration and verification.

FDC plots are illustrated in Figure 4 and Figure 6 for both periods. It is observed that the model does not respond well during low flow period in verification compared to calibration period. In Baddegama, $15 \%$ is a high flow margin and $70 \%$ is a low flow margin. During calibration period, FDC shows a $6.28 \mathrm{~mm} /$ day value of RMSE for high flow and it is slightly underestimated with better matching. Medium flow is showing good matching and slight overestimation with $2.32 \mathrm{~mm} /$ day value of RMSE. Low flow matching shows perfect matching with $1.21 \mathrm{~mm}$ /day value of RMSE. In verification period, FDC shows $7.45 \mathrm{~mm} /$ day value of RMSE for high flow matching and it is underestimated with better matching. The medium flow is matching perfectly with 2.58 $\mathrm{mm} /$ day value of RMSE. Low flow matching at Baddegama shows underestimation with moderate matching of $1.21 \mathrm{~mm} /$ day RMSE value. Watershed's flow duration curve fitting for medium flow is very good and this may lead to a model capable of using in water resource management better than in drought management.

Average annual water balance error is $-0.3 \%$ for $-3 \mathrm{~mm}$ in calibration while it is $-16.7 \%$ for $-187 \mathrm{~mm}$ for verification. As per Table 2, 
2008/09, 2009/10 and 2011/12 in calibration, and 2013/14, 2014/15 and 2015/16 in verification, water years show an underestimation of annual water balance error. Rest of the other two water years, in both calibration and verification, shows overestimation of AWB error. Compared to calibration, verification shows higher magnitude of annual water balance error causing high error in verification. Overall, Baddegama model shows good fit in annual water balance during calibration and verification. Hence, Baddegama model indicates capability of using in water resources and flood management.

\section{Conclusions}

1. A daily HEC HMS model was systematically developed, calibrated and verified for Gin Ganga at Baddegama with RMSE values of 3.0 $\mathrm{mm} /$ day and $3.5 \mathrm{~mm} /$ day during calibration and verification, respectively.

2. Baddegama model with RMSE value of 6.2 $\mathrm{mm} /$ day for high flows and $2.3 \mathrm{~mm} /$ day for medium flows indicate a high capability to model water resources and flood management.

3. The poor low flow matching with 1.21 $\mathrm{mm} /$ day average error during calibration and verification shows that the model cannot be recommended for environmental flow management at daily time scale.

4. Evaluated model component selection, and selection of objective function and evaluation criteria are very important for the development of a watershed model.

\section{Acknowledgement}

The support received from UNESCO Madanjeet Singh Centre for South Asia Water Management, Department of Civil Engineering, University of Moratuwa, Sri Lanka is gratefully acknowledged.

\section{References}

1. Marco, T. A. S., "Water and Sustainable Development: Challenges for Civil Engineers," Water Sustain. Dev., vol. 3, pp. 54-67, 2015.

2. Abimbola, O. P., Wenninger, J., Venneker, R., and Mittelstet, A. R. , "The Assessment of Water Resources in Ungauged Catchments in Rwanda," J. Hydrol. Reg. Stud., vol. 13, pp. 274-289, 2017.

3. Hunter, N. M., Bates, P. D., Horritt, M. S., and Wilson, M. D., "Simple Spatially-
Distributed Models for Predicting Flood Inundation: A Review," Geomorphology, vol. 90, no. 3-4, pp. 208-225, 2007.

4. Loucks, D. P., "Sustainable Water Resources Management," Water Int., vol. 25, no. 1, pp. 3-10, 2000.

5. Fatichi, S., Vivoni, E. R., Ogden, F. L., Ivanov, V. Y., Mirus, B., Gochis, D., Downer, C. W., Camporese, M., Davison, J. H., Ebel, B., Jones, N., Jongho, K., Mascarom, G., Niswonger, R., Restrepo, P., Rigon, R., Shen, C., Sulis, M., David, T.,"An Overview of Current Applications, Challenges, and Future Trends in Distributed Process-Based Models in Hydrology," J. Hydrol., vol. 537, pp. 45-60, 2016.

6. Ojha, C. S. P., Surampalli, R. Y., Bardossy, A., Zhang, T. C. , and Kao, C. M., Sustainable Water Resources Management. 2017.

7. Verma, A. K., Jha, M. K., and Mahana, R. K. , "Evaluation of HEC-HMS and WEPP for Simulating Watershed Runoff Using Remote Sensing and Geographical Information System," Paddy Water Environ., vol. 8, no. 2, pp. 131-144, 2010.

8. Randrianasolo, A. , Ramos, M. H., and Andréassian, V., "Hydrological Ensemble Forecasting at Ungauged Basins: Using Neighbour Catchments for Model Setup and Updating," Adv. Geosci., vol. 29, pp. 1-11, 2011.

9. Cunderlik, J. M., "Hydrologic Model Selection for the CFCAS Project: Assessment of Water Resources Risk and Vulnerability to Changing Climatic Conditions," 2003.

10. Daniel, E. B., Camp, J. V, Leboeuf, E. J., Penrod, J. R., Dobbins, J. P., and. Abkowitz, M. D, "Watershed Modeling and its Applications : A State-of-the-Art Review," pp. 26-50, 2011.

11. Dhami, B. S., and Pandey, A., "Comparative Review of Recently Developed Hydrologic Models," J. Indian Water Resour. Soc., vol. 33, no. 3, pp. 34-42, 2013.

12. Halwatura, D., and Najim, M. M. M., "Application of the HEC-HMS Model for Runoff Simulation in a Tropical Catchment," Environ. Model. Softw., vol. 46, pp. 155-162, 2013.

13. Jayadeera, P. M., and Wijesekera, N. T. S., “A Diagnostic Application of HEC- HMS Model to Evaluate the Potential for Water Management in the Ratnapura Watershed of Kalu Ganga Sri Lanka," Eng. J. Inst. Eng. Sri Lanka, vol. LII, no. 3, pp. 11-21, 2019. 
14. Siriwardana, S. T., and Wijesekera, N. T. S. , "Review of Yield Comparison Options for Planning Irrigation Reservoirs in Ungauged Watersheds," Eng. J. Inst. Eng. Sri Lanka, vol. LIII, no. 01, pp. 77-90 2020.

15. Sampath, D. S., Weerakoon, S. B., and Herath, S., "HEC-HMS Model for Runoff Simulation in a Tropical Catchment with Intra-Basin Diversions - Case Study of the Deduru Oya River Basin, Sri Lanka," Eng. J. Inst. Eng. Sri Lanka, vol. XLVIII, , no. 1, pp. 19, 2015.

16. USACE, “Hydrologic Modelling System HEC-HMS User's Manual," 2016.

17. De Silva, M. M. G. T., Weerakoon, S. B., Herath, S. , Ratnayake, U. R., and Mahanama, S., "Flood Inundation Mapping along the Lower Reach of Kelani River Basin under the Impact of Climatic Change," vol. XXXXV, no. 02, pp. 23-29, 2012.

18. Roy, D., Begam, S., Ghosh, S., and Jana, S. "Calibration and Validation of HEC-HMS Model for a River Basin in Eastern India," J. Eng. Appl. Sci., vol. 8, no. 1, pp. 40-56, 2013.

19. Gumindoga, W., Rwasoka, D. T., Nhapi, I., and Dube, T., "Ungauged Runoff Simulation in Upper Manyame Catchment, Zimbabwe: Application of the HEC-HMS Model," Phys. Chem. Earth, vol. 100, pp. 371-382, 2017.

20. Gebre, S. L., “Application of the HEC-HMS Model for Runoff Simulation of Upper Blue Nile River Basin," Hydrol. Curr. Res., vol. 06, no. 02, 2015.

21. USACE, "Hydrologic Modeling System Technical Reference Manual," 2000.

22. Ahbari, A., Stour, L., Agoumi, A., and Serhir, N., "Estimation of Initial Values of the HMS Model Parameters: Application to the Basin of Bin El Ouidane (Azilal, Morocco)," J. Mater. Environ. Sci., vol. 9, no. 1, pp. 305-317, 2018.

23. Kalita, D. N., "A Study of Basin Response using HEC-HMS and Subzone Reports Of CWC," in 13th National Symposium on Hydrology with focal theme on "Inflow Forecasting during Extremes," 2011.

24. Chow, D. R., Maidment V.T., and Mays, L. W., Applied Hydrology. 1988.

25. Salvadore, E., Bronders, J., and Batelaan, O., "Hydrological Modelling of Urbanized Catchments: A Review and Future Directions," J. Hydrol., vol. 529, pp. 62-81, 2015.
26. Ali, M., Khan, S. J., Aslam, I., and Khan, Z., "Simulation of the Impacts of Land-Use Change on Surface Runoff of Lai Nullah Basin in Islamabad, Pakistan," Landsc. Urban Plan., vol. 102, no. 4, pp. 271-279, 2011.

27. Wijesekera, N. T. S., “A Streamflow Threshold Determination Method for Hydrologic Model Calibration and Verification," Inst. Enginerrs, Sri Lanka, vol. LIII, no. 03, pp. 01-17, 2020.

28. Hamedi A., and Fuentes, H. R., "Comparative Effectiveness and Reliability of NEXRAD Data to Predict Outlet Hydrographs using the GSSHA and HECHMS Hydrologic Models," in World Environmental and Water Resources Congress 2015: Floods, Droughts, and Ecosystems Proceedings of the 2015 World Environmental and Water Resources Congress, 2015, no. July 1997, pp. 1444-1453.

29. Mousavi, S. J., Abbaspour, K. C., Kamali, B., Amini, M. , and Yang, H., "UncertaintyBased Automatic Calibration of HEC-HMS Model Using Sequential Uncertainty Fitting Approach," J. Hydroinformatics, vol. 14, no. 2, pp. 286-309, 2012.

30. Duan, Q., Sorooshian, S., and Gupta, V. K., "Optimal use of the SCE-UA Global Optimization Method for Calibrating Watershed Models," J. Hydrol., vol. 158, pp. 265-284, 1994.

31. Yang, J. , Liu, Y., Yang, W., and Chen, Y., "Multi-Objective Sensitivity Analysis of a Fully Distributed Hydrologic Model WetSpa," Water Resour. Manag., vol. 26, no. 1, pp. 109-128, 2012.

32. Legates, D. R., and McCabe, G. J., "Evaluating the use of 'Oodness-of-fit' Measures in Hydrologic and Hydroclimatic Model Validation," Water Resour. Res., vol. 35, no. 1, pp. 233-241, 1999.

33. Moriasi, D. N., Arnold, J. G., Van Liew, M. W., Bingner, R. L., Harmel, R. D., and Veith, T. L., "Model Evaluation Guideline for Systematic Quantification of Accuracy in Watershed Simulation," Am. Soc. Agric. Biol. Eng., vol. 50, no. 3, pp. 885-900, 2007. 